\title{
The Effect of Transobturator Tape Surgery on Female Sexual Functions: A Systematic Review
}

\author{
Engin YILDIRIM1', Nuriye BUYUKKAYACI DUMAN², Umit GORKEM¹, Ozgur KAN ${ }^{1}$ \\ Corum, Turkey
}

\begin{abstract}
OBJECTIVE: Stress urinary incontinence is one of the diseases that change the quality of life of women. Although there are various medical and surgical treatment modalities exist, transobturator tape surgery is one of the current options with the least complication rates. The aim of this systematic review was to evaluate sexual functional results after the transobturator tape procedure.
\end{abstract}

STUDY DESIGN: Data were taken from those cohort, case-control and cross-sectional studies that were done with human subjects in full texts, were written in the English language.

RESULTS: A total of 24 clinical trials were evaluated. The most frequently administered scales were the female sexual function index and The Pelvic Organ Prolapse/Urinary Incontinence Sexual Questionnaire -12. In total, 8 clinical studies employed female sexual function index whereas 8 clinical studies administered Prolapse/Urinary Incontinence Sexual Questionnaire -12. 4 of these studies tried to understand women's sexual functions through questions determined by the researchers (N/A). 2 of the other studies used the Sexual Impact Questionnaire and a visual analogue scale, 1 study used Nine Questions on Sexual Functioning (NSF-9) and 1 study used International Consultation on Incontinence Questionnaire Vaginal Symptoms Module (ICIQ-VS). It was found that transobturator tape surgery that is performed for incontinence produces positive results on both sexual functions and urinary functions.

CONCLUSION: Maintaining urinary continence is detected to directly be correlated with sexual functions. It is of high importance that before initiating surgical treatments, clinicians should give the patients a detailed medical examination in terms of both urinary and sexual functions.

Keywords: Female sexual function, Transobturator tape, Urinary incontinence

Gynecol Obstet Reprod Med 2020;26(2);155-161

\section{Introduction}

Stress urinary incontinence is involuntary incontinence that occurs when abdominal pressure rises or is provoked by physical activities (1). Involuntary actions such as laughing,

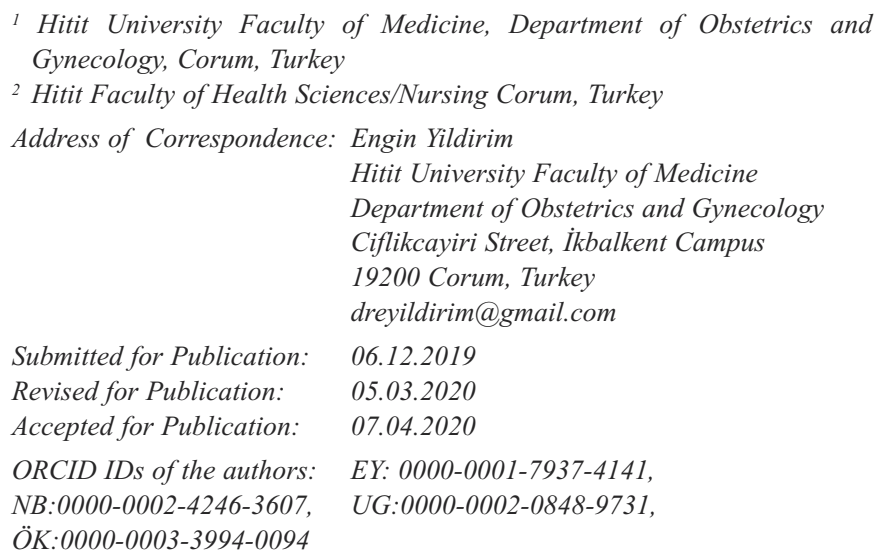

\begin{tabular}{|c|c|}
\hline Quick Response Code: & Access this article online \\
\cline { 2 - 2 } & Website: www.gorm.com.tr \\
& e- mail: info@gorm.com.tr \\
\cline { 2 - 3 } & DOI:10.201613/GORM.2020.1054 \\
\hline
\end{tabular}

How to cite this article: Yildirim E. Buyukkayaci Duman N. Gorkem U. Kan O. Transobturator Tape Surgery on Female Sexual Functions: A Systematic Review. Gynecol Obstet Reprod Med 2020;26(2):155-161 coughing, and sneezing, which increases intraabdominal pressure, can cause urinary incontinence. Social isolation, anxiety, and depression may be observed among some of the women due to incontinence (2). Stress urinary incontinence incidence varies between $40 \%$ and $72 \%$ (3). The parallelism between discomfort patients experience and incontinence severity was found (4).

There is no standard consensus on surgical treatment to be used for stress urinary incontinence. In treating stress urinary incontinence, one-year clinical findings of mid-urethral sling treatments were found to be more successful as compared to pelvic floor strengthening treatments (5). In treating stress urinary incontinence via surgical methods, it was emphasized that mid-urethral sling treatments with propylene mesh are one of the best options (6). In order to minimize bladder perforation and vein damages occurring in sling operations, surgical methods that use obturator canal are recommended. Similar to the use of retropubic tape, the tension-free tape is placed in the mid urethra. Tape adductor is placed upon obturator foramen by perforating muscles and is named as Transobturator tape (TOT) surgery. With this technique, there are methods inside-out or outside-in but these methods are not superior to one other (7). Although healing rates of post- 
surgery stress incontinence differ, 5 years rates vary between $43 \%$ and $92 \%(8)$.

Female sexual life is a complex circle. This circle starts with sexual desire and continues with arousal and orgasm may be interrupted due to some emotional or physiological problems. To determine female sexual life satisfaction is as difficult as to understand the circle. Questions to explore sexual functions are classified by ICS- the International Continence Society and ICI- International Consultation on Incontinence.

These questions can be listed as indexes such as Golombok-Rust Inventory of Sexual Satisfaction (GRISS), Psychosocial Adjustment to Illness Scale (PAIS), Pelvic Organ Prolapse/Urinary Incontinence Sexual Questionnaire (PISQ), Brief Index of Sexual Function for Women (BISF-W) and Female Sexual Function Index (FSFI) (9). Later on, PISQ and FSFI have become the most commonly used scales for assessing pelvic organ functional disorders.

Emotional and social stress caused by stress urinary incontinence influences women's sexual lives, too. Due to stress urinary incontinence, couples' sexual functions and quality of life may be deteriorated (10). After incontinence treatment, positive changes are expected in women's sexual lives. However, the topic of relevant literature provides contradictory data and information. For example, impairments in women's sexual functions were reported following mid-urethral sling surgeries performed before the millennium (11). After TOT surgery, which is used to treat stress urinary incontinence and performed with different modifications, too, various sexual function changes were demonstrated. These studies give different results due to the number of participants, surgical methods, scales used, different meshes and women's ages. With this review; we are aiming at drawing helpful conclusions on sexual results of TOT surgery, which is used for stress urinary incontinence treatment, for clinicians in light of contemporary data.

\section{Material and Method}

While setting up the study, PRISMA-P protocol was used and during data review, this system was applied (12). In the review, clinical studies that assessed the sexual functions of women who received transobturator tape surgery due to genital prolapse and stress urinary incontinence were included. Data were taken from those studies that were done with human subjects in full texts, were written in English language, cohort, case-control and cross-sectional. For clinical cohort studies, a minimum 3-month patient follow-up was essential. In the review, studies published between 2000 and 2018 years were included. Literature was screened in Google Scholar, PubMed, Web of Science and Scopus databases. To screen literature; key words -transobturator tape, female sexual function- were used.
Articles found after searching, those studies that were not written in the English language did not provide correct statistical data, did not provide ethical approval and investigated urge incontinence in methodology were excluded. Data obtained from these studies were gathered in a form and patients' demographic data, study design, finance sources, surgical methods and sexual function indexes used were classified. In order to reduce the bias of the studies investigated in the review, the studies had to use standard scales, to demonstrate rates of participants in groups and the significance and consistency of the statistical data had to be written in full. Studies that did not meet these criteria were excluded from the review.

During literature screening, it was observed that clinical results on female sexual functions after transobturator tape surgery -performed since 2001- have been reported in the literature since 2007. However, the diversity of scales used to identify female sexual functions and new scales developed in the coming years prevented the data from being shared in a standardized pool. In this review, studies were classified in terms of female sexual function scales. In the methodology; data for which sexual function scales were incompletely or partly administered were not examined but presented as (Not Applicable-N/A).

\section{Results}

A total of 24 clinical studies that investigated female sexual function and transobturator tape surgery together and met inclusion criteria were identified in the literature. The date to publish the first study was 2007 while the date to publish the last study was 2017. The number of studies retrospectively done was 2 while the number of the studies prospectively done was 22. Of these studies, there were 5 studies that assessed TOT surgery results alone. 6 of the other studies compared transvaginal tape surgery and TOT surgery, 1 study compared Burch surgery and TOT surgery. In this review, transvaginal tape (TVT) surgeries where obturator canal was used were included and 9 such clinical studies were found (TVT-O) (Table I).

The studies that were investigated in the current review administered various scales that evaluated female sexual function. The most frequently administered scales were the female sexual function index (FSFI) and The Pelvic Organ Prolapse /Urinary Incontinence Sexual Questionnaire -12 (PISQ-12). In total, 8 clinical studies employed FSFI whereas 8 clinical studies administered PISQI-12. 4 of these studies tried to understand women's sexual functions through questions determined by the researchers (N/A). 2 of the other studies used the Sexual Impact Questionnaire and a visual analogue scale (VAS), 1 study used Nine Questions on Sexual Functioning (NSF-9) and 1 study used International Consultation on Incontinence Questionnaire Vaginal Symptoms Module (ICIQ-VS). 
Table I: Short data of research articles

\begin{tabular}{|c|c|c|c|c|c|c|}
\hline Researcher, Year & Surgical Method & Number of patients & $\begin{array}{c}\text { Sexual question in- } \\
\text { dexes }\end{array}$ & $\begin{array}{c}\text { The average } \\
\text { age of patients }\end{array}$ & $\begin{array}{l}\text { Research } \\
\text { method }\end{array}$ & $\begin{array}{l}\text { Follow-Up } \\
\text { Time }\end{array}$ \\
\hline Abdel-Fattah, $(2007)^{30}$ & TOT & TVT-O:94, TOT:182 & $\begin{array}{c}\text { Sexual } \\
\text { Impact Questionnaire } \\
\text { and Visual analogue } \\
\text { scale (VAS) }\end{array}$ & $49(34-78)$ & Retrospective & 28 month \\
\hline Angioli R, $(2010)^{35}$ & TVT vs, TOT & TVT:35, TVT-O:37 & $\mathrm{N} / \mathrm{A}$ & NA & Prospective & 60 month \\
\hline Arts-de Jong, $(2011)^{31}$ & TOT & TOT:54 & $\begin{array}{c}\text { Nine Questions } \\
\text { on Sexual Functioning } \\
\text { (NSF-9) }\end{array}$ & $52(37-78)$ & Prospective & 12 month \\
\hline Barber MD, $(2008)^{24}$ & TVT vs, TOT & TVT:88, TOT:82 & PISQ-12 & $52 \pm 11,53 \pm 12$ & Retrospective & 18 month \\
\hline Cholhan HJ, $(2010)^{20}$ & $\begin{array}{l}\text { TOT vs, } \\
\text { Retropubic Sling }\end{array}$ & TOS:25, RPS:28 & FSFI & $\begin{array}{l}56.6 \pm 14.1 \\
63.1 \pm 11.3\end{array}$ & Retrospective & 10 month \\
\hline $\begin{array}{l}\text { Debodinance P. } \\
(2007)^{32}\end{array}$ & $\begin{array}{l}\text { TVT-O vs, } \\
\text { Monarc }\end{array}$ & $\begin{array}{l}\text { TVT-O:50, } \\
\text { Monarc:50 }\end{array}$ & $\mathrm{N} / \mathrm{A}$ & $\begin{array}{c}54(35-80), 55 \\
(36-80)\end{array}$ & Prospective & 12 month \\
\hline Deffieux X, (2010) $)^{36}$ & TVT vs. TVT-o & TVT:75, TVT-O:74 & $\begin{array}{l}\text { Visual analog scale } \\
\text { ranging; (VAS) }\end{array}$ & $\begin{array}{c}54.6 \pm 10.9 \\
52.8 \pm 9.8\end{array}$ & Prospective & 24 month \\
\hline De Souza A, $(2012)^{26}$ & TVT vs, Monarc & TVT:27, Monarc:27 & PISQ-12 & $55 \pm 9.5,56 \pm 9.3$ & Prospective & 12 month \\
\hline Dursun $\mathrm{M},(2013)^{14}$ & TOT & TOT: 96 & FSFI & $49.2(29-61)$ & Prospective & 6 month \\
\hline El-Enen MA, $(2009)^{15}$ & TOT & TOT: 62 & FSFI & $40.5( \pm 6.1)$ & Prospective & 24 month \\
\hline Elzevier HW, $(2008)^{33}$ & TOT vs, TVT-O & TOT:44, TVT-O:34 & $N / A$ & $52,53,2$ & Prospective & 3 month \\
\hline Karmakar D, (2017) $)^{25}$ & TOT or TVT-O & TOT: 104, TVT-O:104 & PISQ-12 & $59(41-87)$ & Prospective & 81-119 month \\
\hline King AB, $(2013)^{37}$ & TVT-O & TVT-O:42 & $\begin{array}{c}\text { Incontinence } \\
\text { Questionnaire-Vaginal } \\
\text { Symptoms (ICIQ-VS) }\end{array}$ & $61.6 \pm 12.4$ & Prospective & 12 month \\
\hline Lau HH, $(2010)^{27}$ & TVT-O & TVT-O:52 & PISQ-12 & $49.6 \pm 7.0$ & Prospective & 6 month \\
\hline Liang CC, $(2012)^{23}$ & TOT & TOT: 57 & PISQ-12 & $55.4 \pm 12.3$ & Prospective & 12 month \\
\hline Narin $\mathrm{R},(2014)^{16}$ & TOT & TOT:28 & FSFI & $47.75 \pm 6.24$ & Prospective & 3 month \\
\hline Pace G, (2008), ${ }^{19}$ & TVT vs, TOT & TVT:37, ТОТ:71 & FSFI & $\begin{array}{c}59 \text { (38-76), } 55 \\
(36-69)\end{array}$ & Prospective & 12 month \\
\hline Pastore AL, (2016), ${ }^{21}$ & TVT-O vs, SIS & TVT-O:21, SIS:21 & FSFI & $\begin{array}{l}49.8(33-67) \\
50.2(31-68)\end{array}$ & Prospective & 12 month \\
\hline Sentilhes L, (2009), ${ }^{34}$ & TVT vs, TOT & TVT: 84, TOT:64 & N/A & $\begin{array}{l}54.4 \pm 9.0 \\
54.3 \pm 12.7\end{array}$ & Retrospective & 6 month \\
\hline Simsek, A. (2014), ${ }^{17}$ & TOT & ТОт:81 & FSFI & $51.6 \pm 10.3$ & Prospective & 12 month \\
\hline Tang X, (2014), ${ }^{29}$ & $\begin{array}{l}\text { TVT-O vs, } \\
\text { TVT-SECUR }\end{array}$ & $\begin{array}{l}\text { TVT-O:42, } \\
\text { TVT Secur:39 }\end{array}$ & PISQ-12 & $\begin{array}{l}51.3 \pm 7.5 \\
49.8 \pm 10.1\end{array}$ & Prospective & 24 month \\
\hline Tuncer M, (2016), ${ }^{18}$ & TOT vs, BURCH & $\begin{array}{l}\text { TOT: } 49, \\
\text { BURCH:32 }\end{array}$ & FSFI & $\begin{array}{l}48.86 \pm 1.14 \\
51.84 \pm 1.77\end{array}$ & Prospective & 6 month \\
\hline Zhang Z, (2016), ${ }^{28}$ & TVT-O or TVT & TVT-O:70, TVT: 70 & PISQ-12 & $51 \pm 12,55 \pm 12$ & Prospective & 95 month \\
\hline Zyczynski HM, (2012), ${ }^{11}$ & TO-MUS vs, MUS & $\begin{array}{l}\text { TO-MUS:299, } \\
\text { MUS:298 }\end{array}$ & PISQ-12 & $\begin{array}{l}53.1 \pm 11.5 \\
52.7 \pm 10.5\end{array}$ & Prospective & 24 month \\
\hline
\end{tabular}

TOT: Transobturator tape surgery, TVT: Transvaginal tape, TVT-O: Transvaginal tape-obturator foramen used, MUS: Midurethral sling, SIS: Single insicion sling, TO-MUS: Transobturator-midurethral sling, TVT-Secur: Transvaginal tape, Monarc: Monarch sling surgery, PISQ-12: Pelvic organ prolapsus/urinary incontinence sexual questionnaire, FSFI: Female sexual function index, N/A: Not avaible

There were 2857 patients included in the 24 studies that we assessed in this review. The average age of these patients was between $40.5( \pm 6.1)$ and $63.1( \pm 11.3)$. These patients' sexual functions were heterogeneous due to the wide range of sampling.

\section{Comparing FSFI Results}

The female sexual function index (FSFI) is a comprehensive scale that assesses women's desire, arousal, lubrication, orgasm, satisfaction and pain status of patients (13). In this review, it was identified that FSFI was used by 8 studies. There were 4 studies that employed FSFI and examined postopera- tive TOT results. In the prospective study data in which 96 subjects were recruited and the average age was 49.2 (29-61), FSFI scores were found as follows: when postoperative TOT data in the 6th month were compared to preoperative data; the difference was statistically not significant despite a slight rise in sexual desire, arousal, orgasm, and total FSFI scores. However, there were improvements in sexual satisfaction and dyspareunia scores and these were statistically significant (14). We are of the opinion that the limitation of this study was the number of participants and cohort time. Similarly; in a prospective study done in 2009 where 62 TOT surgery patients participated, it was noted that there were increases in 
FSFI total scores, sexual desire, arousal, satisfaction, and lubrication. Besides, this study indicated that after 8 weeks following the surgery, women became able to have a sexual relationship once a week (15).

It is very important to return to normal daily life after TOT surgery, to fulfill normal micturition functions and to lead a previous sexual life. It is also important to protect sexually active women's social lives with their partners. There are also data with which sexual functions were assessed using FSFI in the short term after TOT surgery. In the prospective study of Narin et al. done with 28 participants; FSFI total scores were compared at month 3 before and after the surgery. Total FSFI scores increased and that increase was statistically significant. The logical part of this study was that it assessed the sexual functions of male partners before and after TOT surgery. These functions were studied with the international erectile function index (IIEF) and it was found that the partner's IEEF scores increased statistically and significantly after 3 months following the TOT treatment of women. (16). In a study involving eighteen women, although most women remained unchanged after the transobturator mid-urethral sling procedure, a significant percentage of the sexual partners in the study felt their sexual activity improved after surgery (17). Another study that followed the effect of TOT surgery on sexual functions for 1 year has been shown to improve coital incontinence and sexual desire (18).

Complications of TOT surgery are among those factors that may affect postoperative recovery processes and female sexual functions. In a prospective TOT surgery series in which a total of 81 participants were recruited, FSFI scores of 13 complicated patients were compared to those of 68 non-complicated patients. According to prevalence order (higher number first), complications detected were mesh erosion, de novo urge incontinence, postoperative urinary retention and vesicovaginal fistula (in one patient). When preoperative and postoperative FSFI scores were compared, total scores elevated in non-complicated patients whereas these scores did not elevate in complicated patients. When post-surgery FSFI scores of both groups were compared, scores of complicated patients clearly went down and the difference was found to statistically be significant (19).

There are no studies that compared TOT surgery to other incontinence surgeries. In a study in which TOT surgery and the Burch colposuspension surgery were compared with each other, no statistically significant difference existed between preoperative and postoperative total FSFI scores for both surgeries. However, the group of TOT surgery demonstrated significant improvements in postoperative desire scores (20). In another study in which FSFI scores of TVT and TOT surgeries were compared, it was demonstrated that both surgeries improved postoperative sexual functions and it was concluded that these methods were not superior to one another in terms of FSFI (21). In a study in which Transobturator sling surgery and retropubic sling surgery were compared, no difference was found in postoperative FSFI scores and it was shown that paraurethral bands may cause dyspareunia (22). In a prospective study where the obturator canal was used for incontinence treatment, FSFI scores of Tension-Free Transobturator Suburethral Tape (TVT-O) and Suburethral Single-Incision Sling (SIS) treatments were evaluated. Both methods produced better FSFI scores in post-surgery as compared to presurgery significantly. However, no statistically significant difference was identified in terms of postoperative FSFI scores of both methods and neither of the methods was superior to one another in terms of sexual functions (23).

\section{Comparing PISQ-12 results}

Pelvic organ prolapse/Urinary Incontinence Sexual Questionnaire (PISQ-12) is a repeatable and reliable scale to assess the sexual functions of women with urinary incontinence and pelvic organ prolapse (24). PISQ-12 provides a single sexual function score that contains behavioral/emotional domain, physical domain, and partner-related domain. In the current review; it was found that 8 studies administered the PISQ-12 scale and only one study assessed patients who received TOT surgery alone. In this study, a total of 83 women were examined and it was found that 57 women lead active sexual life whereas 26 women did not lead to active sexual life. A statistically significant difference existed between sexually active and inactive women in the average age but the average age of inactive women was higher. Women who underwent TOT surgery due to incontinence were followed up for 12 months and no statistically significant difference was found in total PISQ-12 scores. Yet, it was observed that during the follow-up, PISQ-12 scores on incontinence (coital incontinence and coital incontinence fear) improved while PISQ-12 scores on a climax with intercourse and emotional status worsened (25).

PISQ-12 scores of TOT procedure were compared to different incontinence surgery procedures. 88 TVT surgery patients and 82 TOT surgery patients were followed up for one year. As a result of follow-up, it was noted that patient groups who received these procedures demonstrated better postoperative PISQ-12 scores than preoperative scores. Sexual functions of both groups improved after surgeries but no statistically significant difference was detected in postoperative PISQ-12 scores of both groups. It was concluded that it is certain that TVT and TOT procedures produced healing effects on sexual functions but neither of the two procedures was superior to one another in terms of sexual function (26). In a newer study in which inside-out TVT surgery -passing through obturator foramen- was compared to outside-in TVT surgery; it was concluded that both methods improved postoperative PISQ-12 scores and no difference was found in postoperative sexual function scores of both procedures (27). In another study in which TVT procedure was compared to 
Monarch Sling surgery -dorsal clitoris nerves operated-, PISQ-12 scores were assessed at month 6 and at month 12 . After both procedures, progresses in sexual functions was achieved but PISQ-12 scores were higher at month 6 in the TVT surgery group. At the end of the first year, neither of the procedures was superior to one another in terms of sexual function scores (28).

Clinical results of the methods in which transobturator canal was used were similar due to obturator nerve and vein proximity. In a study in which short term postoperative sexual function of sexually active women operated using TVT-O procedure was examined, it was seen that no increase existed in PISQ-12 scores. In light of these findings, it was concluded that TVT-O surgery did not have any positive effects upon sexual functions during the first six months' period and different results were obtained from other studies in the literature (29). The longest-term results of TVT and TVT-O surgeries were obtained performing a 95-month follow-up. In this study, 58 women with TVT surgery were compared to 62 women with TVT-O surgery. Since the follow-up period was long, a limited number of women with sexual activity were compared. 32 of these women received TVT whereas 37 women received TVT-O surgery. After 95 months follow-up, no statistical difference was found between preoperative and postoperative PISQ-12 scores and no change in sexual functions was seen. The reason may have been that most of these women had already entered the menopause by the time 95thmonth control arrived (30).

Although mechanisms of sling surgeries on pathologies are similar to each other, anatomic methods used and postoperative outcomes vary considerably. In a large study, sexual functions of 299 women who underwent transobturator midurethral sling surgery and 298 women who underwent retropubic mid-urethral sling surgery were compared. At the end of the 2-year follow-up, their postoperative sexual functions improved. Both groups showed an evident improvement in fear of incontinence and incontinence experienced during sexual intercourse. However, urge incontinence complaints of both groups did not differ (11). It seems to be a plausible hypothesis that surgical methods in which vaginal incision and suturing are performed on a small scale will have positive effects on sexual functions. In a study where TVT-O procedure was compared to TVT-SECUR, which has a single vaginal incision advantage, it was identified that among preoperative and postoperative PISQ-12 scores, improvements were seen in the physical domain. No statistically significant difference was found between 12-month follow-up scores and 24-month follow-up scores (31).

\section{Other Sexual Function Scales and Subjective Assessments}

There are also some other studies that employed sexual function scales that assess female sexual functions but are rarely used. In 2007, a study was done by investigating 276 patients explored that after 182 TOT surgeries, neither did the frequency of sexual intercourse reduce nor were dyspareunia and sexual satisfaction disorders experienced but coital incontinence decreased considerably (32). In another study where 54 sexually active women were followed up until postoperative 12th month following TOT surgery, the Nine Questions on Sexual Functioning (NSF-9) and its scoring system were used in order to evaluate sexual function. It was suggested that TOT surgery decreased dyspareunia and coital incontinence (33).

In another study in which the effect of TVT-O surgery upon postoperative sexual functions using subjective questions, sexual life efficiency questions were asked but it was argued that no negative answers were given (34). In a study in which TVT surgery was compared to TOT, it was found that TOT patients had some vaginal narrowing during the postoperative period (35). In another study in which TVT surgery and TOT surgery were compared, $17.3 \%$ of TVT patients and $12.5 \%$ of TOT patients suffered from sexual function disorders in the postoperative period (36). In a study that shared 5year follow-up data after TVT and TVT-O procedures, it was stated that the most commonly marked complaints of patients were dyspareunia (37).

Postoperative sexual status of women who receive TVT and TVT-O surgeries may be assessed using Visual analog scales (VAS 0-100) scores and The International Consultation on Incontinence Questionnaire-Vaginal (ICIQ-VS). In the first study, 74 TVT-O and 75 TVT patients were compared and after a 24-month follow-up, both groups of patients showed better postoperative VAS scores. This improvement was attributed to a decrease in urinary leakage (38). In the second study, vaginal symptoms of 42 patients were studied using ICIQ-VS after TVT-O. All of 1 and 2-year follow-ups detected increases in scores and decreases in dyspareunia complaints (39).

\section{Discussion}

At the end of this review, it was concluded that progress in sexual functions occurred after incontinence surgeries. This progress was clearer in coital incontinence and fear of incontinence. It was identified that there was only one study that assessed sexual functions with male partners and in this study, male sexual functions improved, too. Of surgical techniques, TOT surgery and TVT surgery were most compared. On the other hand, there were also other studies in which new incontinence surgery tools, single incision tools, and colposuspension surgeries were compared, too. There were no studies that proved that these methods were superior to one another in terms of correcting total sexual functions.

On the other side, there were also some studies in which improvements in female sexual functions were not observed. It was found that in these studies, time to assess the participants was either shorter than one year or longer than five 
years. In particular, no progress in sexual functions was observed among patients with advanced ages, surgical complications, and preoperative period urge incontinence.

In scales where sexual functions were evaluated, it was observed that postoperative improvements in climax with intercourse and emotional status were smaller. It was identified that some women may postoperatively experience dyspareunia and vaginal pain. Some other studies where TVT and TOT surgeries were compared showed vaginal narrowing after TOT surgery and sexual function disorders after TVT surgery, though subjectively.

\section{Conclusion}

It was found that TOT surgery that is performed for incontinence produces positive results on both sexual functions and urinary functions. It was proven that FSFI and PISQ-12 scoring indexes provide successful data to standardize these results. Maintaining urinary continence is detected to directly be correlated with sexual functions. It is of high importance that before initiating surgical treatments, clinicians should give the patients a detailed medical examination in terms of both urinary and sexual functions.

Acknowledgments: We thank the staff of the gynecology unit Disclosure statement: The authors declare that they have no conflict of interest.

Funding: This research was supported by the authors.

Ethical approval: Not applicable.

Informed consent: Not applicable.

Author contribution: EY: Study design, data collection, analysis and writing. NBD; Study design, UG; Data collection. OK: Analysis and writing.

\section{References}

1. Nygaard I, Barber MD, Burgio KL, Kenton K, Meikle S, Schaffer J, et al. Pelvic Floor Disorders Network. Prevalence of symptomatic pelvic floor disorders in US women. JAMA. 2008;300(11):1311-6.

2. Broome BA. The impact of urinary incontinence on self efficacy and quality of life. Health Qual Life Outcomes $2003 ; 1: 35$.

3. Swithinbank LV, Donovan JL, du Heaume JC, Rogers CA, James MC, Yang Q, et al. Urinary symptoms and incontinence in women: relationships between occurrence, age, and perceived impact. Br J Gen Pract. 1999;49(448):897900.

4. Fultz NH, Burgio K, Diokno AC, Kinchen KS, Obenchain $\mathrm{R}$, Bump RC. Burden of stress urinary incontinence for community-dwelling women. Am J Obstet Gynecol. 2003;189(5):1275-82.

5. Labrie J, Berghmans BL, Fischer K, Milani AL, van der Wijk I, Smalbraak DJ, et al. Surgery versus physiotherapy for stress urinary incontinence. N Engl J Med. 2013;369 (12):1124-33.

6. Chapple CR, Cruz F, Deffieux X, Milani AL, Arlandis S, Artibani W, et al. Consensus Statement of the European Urology Association and the European Urogynaecological Association on the Use of Implanted Materials for Treating Pelvic Organ Prolapse and Stress Urinary Incontinence. Eur Urol. 2017;72(3):424-31.

7. Serati M, Braga A, Athanasiou S, Tommaselli GA, Caccia $\mathrm{G}$, Torella M, et al. Tension-free vaginal tape-obturator for treatment of pure urodynamic stress urinary incontinence: efficacy and adverse effects at 10-year follow-up. Eur Urol. 2017;71(4):674-9.

8. Ford AA, Rogerson L, Cody JD, Aluko P, Ogah JA. Midurethral sling operations for stress urinary incontinence in women. Cochrane Database Syst Rev. 2017;(7):CD00 6375 .

9. Abrams PCL, Khoury S, Wein A (eds). Incontinence, 3rd international consultation on incontinence. Health Publications Ltd: Paris, France, 2005; p.541-5.

10. Lim R, Liong ML, Leong WS, Khan NA, Yuen KH. Effect of Stress Urinary Incontinence on the Sexual Function of Couples and the Quality of Life of Patients. J Urol. 2016;196(1):153-8.

11. Zyczynski HM, Rickey L, Dyer KY, Wilson T, Stoddard AM, Gormley EA, et al. Urinary Incontinence Treatment Network. Sexual activity and function in women more than 2 years after midurethral sling placement. Am J Obstet Gynecol. 2012;207(5):421.e1-6.

12. Moher D, Shamseer L, Clarke M, Ghersi D, Liberati A, Petticrew M, et al. PRISMA-P Group. Preferred reporting items for systematic review and meta-analysis protocols (PRISMA-P) 2015 statement. Syst Rev. 2015;4:1.

13. Rosen R, Brown C, Heiman J, Leiblum S, Meston C, Shabsigh R, et al. The Female Sexual Function Index (FSFI): a multidimensional self-report instrument for the assessment of female sexual function. J Sex Marital Ther. 2000;26(2):191-208.

14. Dursun M, Otunctemur A, Ozbek E, Cakir SS, Polat EC. Impact of the transobturator tape procedure on sexual function in women with stress urinary incontinence. J Obstet Gynaecol Res. 2013;39(4):831-5.

15. El-Enen MA, Ragb M, El Gamasy Ael-N, El-Ashry O, ElSharaby M, Elbadawy A, et al. Sexual function among women with stress incontinence after using transobturator vaginal tape, and its correlation with patient's expectations. BJU Int. 2009;104(8):1118-23.

16. Narin R, Attar R, Narin MA, Koyuncu D, Yencilek E. Impact of transobturator tape procedure on female and their partner sexual function: it improves sexual function of couples. Arch Gynecol Obstet. 2014;290(5):913-7.

17. Hsiao SM, Lin HH. Impact of the mid-urethral sling for stress urinary incontinence on female sexual function and 
their partners' sexual activity. Taiwan J Obstet Gynecol. 2018;57(6):853-7.

18. Aslan E, Gungor Ugurlucan F, Bilgic D, Yalcin O, Kizilkaya Beji N. Effects of transobturator midurethral sling surgery on sexual functions: one-year follow-up. Gynecol Obstet Invest. 2018;83(2):187-97.

19. Simsek A, Ozgor F, Yuksel B, Kucuktopcu O, Kirecci SL, Toptas M, et al. Female sexual function after transobturator tape in women with urodynamic stress urinary incontinence. Springerplus. 2014;3:570.

20. Tuncer M, Tarhan F, Kafkasli A, Demir K, Yucetas U, Faydaci $\mathrm{G}$, et al. The effects of stress incontinence surgery on sexual function and life quality of women. Arch Ital Urol Androl. 2016;88(2):106-10.

21. Pace G, Vicentini C. Female sexual function evaluation of the tension-free vaginal tape (TVT) and transobturator suburethral tape (TOT) incontinence surgery: results of a prospective study. J Sex Med. 2008;5(2):387-93.

22. Cholhan HJ, Hutchings TB, Rooney KE. Dyspareunia associated with paraurethral banding in the transobturator sling. Am J Obstet Gynecol. 2010;202(5):481.e1-5.

23. Pastore AL, Palleschi G, Al Salhi Y, Riganelli L, Fuschi A, Autieri D, et al. Evaluation of sexual function and quality of life in women treated for stress urinary incontinence: tension-free transobturator suburethral tape versus singleincision sling. J Womens Health (Larchmt). 2016;25(4): 355-9.

24. Rogers RG, Coates KW, Kammerer-Doak D, Khalsa S, Qualls C. A short form of the Pelvic Organ Prolapse/ Urinary Incontinence Sexual Questionnaire (PISQ-12). Int Urogynecol J Pelvic Floor Dysfunct. 2003;14(3):164-8; discussion 168 .

25. Liang CC, Tseng LH, Lo TS, Lin YH, Lin YJ, Chang SD. Sexual function following outside-in transobturator midurethral sling procedures: a prospective study. Int Urogynecol J. 2012;23(12):1693-8.

26. Barber MD, Kleeman S, Karram MM, Paraiso MF, Walters MD, Vasavada S, et al. Transobturator tape compared with tension-free vaginal tape for the treatment of stress urinary incontinence: a randomized controlled trial. Obstet Gynecol. 2008;111(3):611-21.

27. Karmakar D, Mostafa A, Abdel-Fattah M. Long-term outcomes of transobturator tapes in women with stress urinary incontinence: E-TOT randomised controlled trial. BJOG. 2017;124(6):973-81.

28. De Souza A, Dwyer PL, Rosamilia A, Hiscock R, Lim YN, Murray C, et al. Sexual function following retropubic TVT and transobturator Monarc sling in women with intrinsic sphincter deficiency: a multicentre prospective study. Int Urogynecol J. 2012;23(2):153-8.

29. Lau HH, Su TH, Su CH, Lee MY, Sun FJ. Short-term impact of tension-free vaginal tape obturator procedure on sexual function in women with stress urinary incontinence. J Sex Med. 2010;7(4 Pt 1):1578-84.

30. Zhang Z, Zhu L, Xu T, Lang J. Retropubic tension-free vaginal tape and inside-out transobturator tape: a long-term randomized trial. Int Urogynecol J. 2016;27(1):103-11.

31. Tang X, Zhu L, Liang S, Lang J. Outcome and sexual function after transobturator tape procedure versus tension-free vaginal tape SECUR: a randomized controlled trial. Menopause. 2014;21(6):641-5.

32. Abdel-Fattah M, Ramsay I, Pringle S, Bjornsson S. Transobturator suburethral tapes in the management of urinary incontinence: success, safety and impact on sexual life. Gynecological Surgery, 2007;4(4):267-73.

33. Arts-de Jong M, van Altena AM, Aalders CI, Dijkhuizen FP, van Balken MR.Improvement of sexual function after transobturator tape procedure in women with stress urinary incontinence. Gynecological surgery. 2011;8(3):315-9.

34. Debodinance P. Trans-obturator urethral sling for the surgical correction of female stress urinary incontinence: outside-in (Monarc) versus inside-out (TVT-O). Are the two ways reassuring? Eur J Obstet Gynecol Reprod Biol. 2007;133(2):232-8.

35. Elzevier HW, Putter H, Delaere KP, Venema PL, Lycklama à Nijeholt AA, Pelger RC. Female sexual function after surgery for stress urinary incontinence: transobturator suburethral tape vs. tension-free vaginal tape obturator. J Sex Med. 2008;5(2):400-6.

36. Sentilhes L, Berthier A, Loisel C, Descamps P, Marpeau L, Grise P. Female sexual function following surgery for stress urinary incontinence: tension-free vaginal versus transobturator tape procedure. Int Urogynecol J Pelvic Floor Dysfunct. 2009;20(4):393-9.

37. Angioli R, Plotti F, Muzii L, Montera R, Panici PB, Zullo MA. Tension-free vaginal tape versus transobturator suburethral tape: five-year follow-up results of a prospective, randomised trial. Eur Urol. 2010;58(5):671-7.

38. Deffieux X, Daher N, Mansoor A, Debodinance P, Muhlstein J, Fernandez H. Transobturator TVT-O versus retropubic TVT: results of a multicenter randomized controlled trial at 24 months follow-up. Int Urogynecol J. 2010;21(11):1337-45.

39. King AB, Wolters JP, Klausner AP, Rapp DE. Vaginal symptoms and sexual function after tension-free vaginal tape-obturator placement: minimum 12-month follow-up. Urology. 2013;81(1):50-4. 